\title{
Cultura Cubana Y Medios DE COMUNICACIÓN EN MÉXICO, 1920-1950
}

\author{
Cuban Culture and Mass media in México, 1920-1950
}

\author{
Por: Ricardo Pérez Montfort, CIESAS* \\ Gabriela Pulido Llano, DEH-INAH** \\ Artículo Recibido: Octubre 24 de 2011. Artículo aprobado: Diciembre 05 de 2011
}

* RICARDO PERTFORT

Doctor en Historia, Universidad Nacional Autónoma de

México. Pertenece al Centro

de Investigaciones y Estudios

Superiores en Antropología Social (CIESAS). E-mail: rpmont54@yahoo.com.mx

** GABRIELA PULIDO

LLANO.

Candidata a doctor en Historia y Etnohistoria, Escuel nacional de antropología de México. Pertenece a la Dirección de Estudios Históricos del Instituto Nacional de Antropología e Historia. E-mail: azuucar@yahoo.com.mx

Artículo de reflexión según clasificación Colciencias.

\section{RESUMEN}

En este artículo estudiamos las huellas que la cultura popular cubana, durante la primera mitad del siglo XX, imprimió en la cultura popular mexicana, a través de los medios de comunicación; estamos hablando de la prensa, el radio y el cine, en particular. Este proceso muestra cómo las características de los estereotipos culturales identificados con lo cubano, resultaron un producto de exportación que los medios mexicanos supieron aprovechar de maneras muy creativas. Esto puede rastrearse, en particular, en la música y el cine producidos en los años treinta y cuarenta. Los teatros, salones de baile y cabarets fueron otros espacios en los que este imaginario cobró forma. Detrás de esto hubo una nutrida migración de artistas cubanos que contribuyeron a la manufactura de una vertiente de la cultura popular mexicana asociada a lo tropical. La relación personal entre estos cubanos y cubanas, y sus comparsas mexicanos, así como los vínculos que muchos de los oriundos de la Gran Antilla tuvieron con empresarios del espectáculo y, productores y directores de cine en México, fueron pieza clave en esta historia.

Palabras clave: Cultura popular, esteoripos culturales, medios de comunicación, música, cine, cultura cubana.

\section{ABSTRACT}

In this article we study the traces that cuban popular culture, left on mexican popular culture, via press, radio and cinema, during the first decades of the 20th century. this process shows how cultural stereotype characteristics identified with cubanity, became an exportable product, which media in mexico they knew how to exploit with lots of creative resources. the can be tracked, particularly, on music and cinema produced during 1930 and 1940. theaters, dance halls and cabarets were spaces in which this imaginary was shaped. behind this scene there was a large artistic migration from cuba that contributed on the manufacture of an aspect of mexican popular culture associated with tropicality. personal relationships between cuban and mexican artists, such as their bonds with show-businessmen an cinema producers and directors, are a key in history.

Keywords: Popular culture, cultural stereotype, mass media, music, cinema, Cuban cultura. 


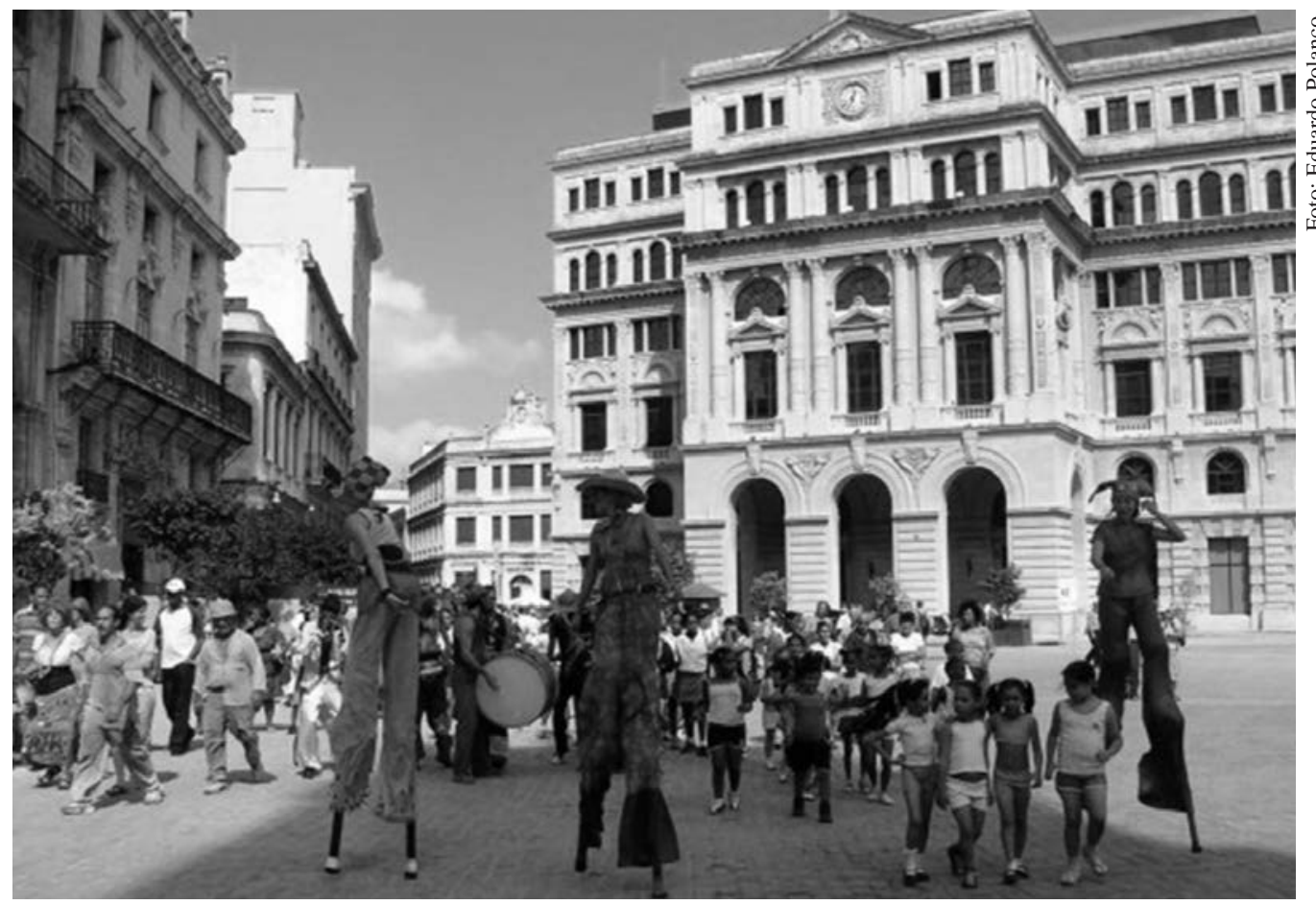

Desfile infantil en la Habana. 2007

En el presente ensayo pretendemos seguir las huellas de algunas vertientes identificadas con la cultura popular cubana, de la primera mitad del siglo $\mathrm{XX}$, las mismas que fueron explotadas por los medios de comunicación en México. La búsqueda de diversos rastros narrativos, musicales y visuales, de lo que eventualmente sería identificado como "la expresión popular de Cuba", a través de dichos medios, nos permite aproximarnos a una serie de facetas que influyeron de manera determinante en la construcción de vertientes culturales populares, tanto discursivas como imaginarias. La contribución "cubana" formó así un núcleo importante en la constelación de elementos que se dieron cita a la hora de armar el complejo universo que hemos llamado cultura popular mexicana.

A partir de la década de los años veinte del siglo pasado, la construcción de dicha cultura pasó indefectiblemente a través de los medios de comunicación masiva. En primera instancia, la prensa popular, seguida por la incipiente industria radiofónica y su posterior desenvolvimiento en el cine sonoro, así como el impulso particular del teatro de revista y del mundo del cabaret y la carpa, fueron determinantes para el apuntalamiento de esa cultura popular. Combinando cierta nostalgia del mundo rural con las glorias y los defectos de la vida urbana, poco a poco, la cultura popular empezó a tener un fuerte sabor 
${ }^{1}$ Ricardo Pérez Montfort, Expresiones populares y estereotipos culturales en México. Siglo XIX y XX

Diez ensayos, CIESAS,

México, 2007.

2 Gustavo García y Rafael Aviña , Época de oro del cine mexicano, México, Editorial Clío, México, 1997.

3 Fernando Muñoz Castillo, Las reinas del trópico, México, Azabache, 1993, pág. 16.

4 Francisco Sánchez, Crónica antisolemne del cine mexicano, México, Universidad Veracruzana, 1989. cosmopolita, que no solamente incorporó valores nacionalistas, sino que abrió su mirada sobre todo al mundo estadounidense y latinoamericano. En esta última esfera de influencia la combinación de cabaret y música afroantillana se convirtió en una referencia obligada a la hora de hacer un recuento de la diversión y el ocio de múltiples sectores de la sociedad mexicana. Tan es así que se instauró una vertiente cultural o si se quiere un género tanto musical, como de baile e incluso como "modo de vida", que fue conocido como el de las "rumberas".

Ya en la década de los años cuarenta, este género de "rumberas" sirvió como promotor de diversas expresiones culturales cubanas que no tardaron en convertirse en lugares comunes o si se quiere en "estereotipos culturales". ${ }^{1}$ El aumento paulatino de la presencia de estos estereotipos en el cine y en el cabaret mexicanos puede sentirse a partir de los primeros años treinta. Dicen Gustavo García y Rafael Aviña que, "los ritmos afroantillanos llegaron a finales de los años veinte y entraron al cine mediante un número musical en "Santa" (1931), otro más espectacular en "Aguila o Sol" (1939) a cargo de Margarita Mora y una rumba clásica importada por Juan Orol para "El calvario de una esposa" (1936)..."2 interpretada por Consuelo Moreno. La puertorriqueña Mapy Cortes fue considerada como una de las primeras rumberas, sin embargo quienes llevarían el género y los bailables rumberos a niveles inverosímiles serían las cubanas María Antonieta Pons, Ninón Sevilla y Amalia Aguilar.

Emilio García Riera, citado por Fernando Muñoz Castillo, señalaría que "de 3 películas de rumberas en 1946, se filmaron 13 en 1947, 25 en 1948 y 50 en 1950; en 1952 se filmaron 21 películas con el tema y a partir de 1953 el número fue disminuyendo hasta casi desaparecer a finales del sexenio del Lic. Ruiz Cortines". ${ }^{3}$ Aún cuando la mayoría de estas películas se filmaron cuando ya había pasado el gobierno de Miguel Alemán, éste sería recordado como el sexenio del cine de cabareteras. Reñido de cierta manera con las aportaciones estéticas pero muy complaciente con los bajos presupuestos este cine de rumberas o exóticas pareció inspirado en la vertiente de sublimación de la mujer-prostituta-buena que respondía a los sobrenombres que Agustín Lara les asestaba de la siguiente manera: Mala hembra, Callejera, Pecadora, Trotacalles, Perdida, Hipócrita o Aventurera. ${ }^{4}$ Sin embargo para llegar a estas propuestas visuales de celuloide cabareteril y afroantillano de gran escala promocional, habría que considerar otros espacios y otras vertientes. 
Como ya se dijo, durante la primera mitad del siglo $\mathrm{XX}$, los emergentes medios de comunicación masiva mexicanos participaron determinatemente en la construcción de una de las múltiples vertientes de la cultura popular caribeña: la música afrocubana y su imagen. Músicos, actores y actrices provenientes de la Gran Antilla difundieron sus producciones musicales y coreográficas, sus formas de representarse y sus visiones de lo que "debía ser" el mundo caribeño, a partir de una interpretación muy particular que ellos mismos hacían de sus expresiones y ambientes. Los medios de comunicación mexicanos los aceptaron y moldearon de tal manera que no tardaron en invadir el universo recreativo nacional, y su paulatina proyección internacional. A su vez, diversos personajes populares representativos de la escena mexicana se adscribieron a estos géneros musicales y bailables, logrando apuntalar una serie de imágenes características de lo que para ellos era la cultura popular del Caribe desde los años 20 hasta los primeros años 50 del siglo XX. Mulatas, bongoseros, bailarines, cantantes "anegrados", haciendo constates giros lingüísticos cubanos o antillanos, orquestas estridentes y rítmicas, coreografías con mucho meneo de cadera, escenografías plagadas de referencias tropicales y afroides, se convirtieron en referencias imprescindibles del mundo musical y escénico mexicano.

Mirando de cerca las experiencias de artistas cubanos como Rita Montaner, Ignacio Villa "Bola de Nieve", Sindo Garay, María Antonieta Pons, Amalia Aguilar, Rosa Carmina, Kiko Mendive, Benny Moré, Dámaso Pérez Prado, Silvestre Méndez, por mencionar solo algunos, podemos adentrarnos en esta vertiente de la vida urbana popular del México de la primer mitad del siglo XX, y de sus propuestas para atacar los mercados internacionales. La adopción de muchos de sus estilos por parte de una buena cantidad de artistas y músicos mexicanos dieron la nota para afianzar la popularización de la "cubanía" o si se quiere "el tropicalismo" nacional. Figuras como Toña la Negra, Meche Barba, Agustín Lara, Pedro Vargas, Pedro Infante, Germán Valdéz “Tin Tan”, tan solo por mencionar unos cuantos, aumentaron su popularidad en gran medida al tomar prestados algunos de estos elementos de "cubanismo" o por lo menos del mundo de la música afrocubana.

El ir y venir de factores considerados como "esencias" de la cultura popular cubana, reforzados por los medios de comunicación masiva mexicanos, dio lugar a una visión muy particular del mundo antillano. ${ }^{5}$ El análisis de estos casos particulares permite comprender algunos mecanismos de introducción de lo que hemos querido identificar como "estereotipos
5 En el núcleo de estas disposiciones esenciales se plantean que hay cuestiones que no cambian con el tiempo, que siempre han estado ahí, que son la marca distintiyue son la marca distintiva del deber ser" cubano. Piénsese en factores como la facilidad para interpretar y bailar música rítmica cierta coloración en la piel - la manera de vestirse o l andar generalmente de buen humor, vid. Ricardo Pérez Montfort "Folklore e identidad, Reflexiones sobre una herencia nacionalista en América" en Avatares del nacionalismo cultural. Cinco ensayos, CIESAS CIDEHM, México, 2000. 
6 Véanse tan sólo: Laura Muñoz (coord.) México y el Caribe. Vínculos, intereses región, 2 tomos, Instituto Mora, México, 2002 y Bernardo García Díaz y Sergio Guerra Vilaboy (coord..) La Habana /Veracruz. Veracruz/La Habana. Las dos orillas Universidad Veracruzana, Universidad cruzana, Universidad de La culturales cubanos", en los referentes de la cultura popular mexicana. Desde aquí estos estereotipos saltaron hacia los medios de comunicación tanto de América del Norte como de Sudamérica y Europa. De esta manera consideramos que fue sobre todo a través de los medios mexicanos que se permitió la proyección y difusión de estos fenómenos culturales, en diversos mercados internacionales.

Muchos cubanos vinculados al espectáculo se dirigieron a México a través de distintas oleadas y por diferentes motivos. Si bien ya se había sentido su relevancia desde finales del siglo XIX, esta migración se intensificó durante los años que van de 1920 a 1960, justo cuando los medios de comunicación masivos mexicanos se desarrollaron de manera puntual y constante. Una caracterización general describe la llegada de estos personajes a través de dos etapas durante la primera mitad del siglo XX: una primera que va de 1920 a 1939, y una segunda que va de 1940 a 1959-1960. Tanto la Segunda Guerra Mundial como el triunfo de la Revolución Cubana tuvieron una influencia central en esta migración. La primera permitió la proyección masiva tanto de la industria fonográfica como del cine mexicanos en el mercado sudamericano, y la segunda porque le dio cierto tono político, ya fuera a favor o en contra, a las circunstancias que determinaban el intercambio cultural entre Cuba y México. Si bien la primera influye determinantemente en el universo que aquí tratamos, la segunda ya ha merecido diversos estudios que rebasan las intenciones de este trabajo. ${ }^{6}$

En la mayoría de los casos, el desplazamiento de músicos y actores estuvo ligado a las empresas artísticas, tanto cubanas como mexicanas, que posibilitaron un primer momento de salida de la isla y el arribo a México. Un ejemplo, es el del conjunto musical Son Cuba de Marianao que en 1928, fue traída de La Habana por el empresario José R. Campillo y llevó a cabo sus primeras representaciones capitalinas en el Teatro Esperanza Iris. Llegaron a México y se hospedaron cerca del Salón México. En 1930, Arsenio Núñez Molina, guitarrista, y Eulalio Ruiz de Mantilla, tresista, ambos integrantes de esta agrupación, tomaron la decisión de quedarse en México. De igual manera algunos personajes como Juan Orol, Ramón Peón y René Cardona, el primero nacido en España y los dos últimos cubanos, comenzaron sus carreras como intermediarios, aunque con el paso de los años serían verdaderos estrategas en la demanda del espectáculo tropical en México, esto sin contar sus aportaciones particulares a la industria cinematográfica mexicana. 
Para poder entender este largo proceso de creación de la imagen del mundo caribeño y su difusión, sería necesario analizar los múltiples procedimientos determinados por las prioridades del mercado artístico popular. Aquí solo haremos referencia a unos cuantos.

\section{II}

Los artistas y las expresiones culturales ligados a la música y al baile cubanos tuvieron que atravesar por caminos muy diversos para consolidar sus trayectorias en los medios mexicanos. Hubo quienes empezaron cargando los instrumentos de las orquestas, para sobrevivir, y aprendieron el oficio del músico en la marcha. Esos fueron los casos de Dámaso Pérez Prado y del propio Consejo Valiente mejor conocido como "Acerina".

Desde las primeras décadas del siglo XX la tradición danzonera y sonera cubana, generó una sólida corriente musical en el puerto de Veracruz y en la península de Yucatán, dando lugar a un estilo muy especial de tocar el danzón y el son, una manera veracruzana o yucateca de sonear, por decirlo así. La influencia cubana llegó a demostrarse, por ejemplo, en el estilo del gran tresero el Negro Peregrino, hermano de Toña la Negra, asi como en una infinidad de grupos como el Son Jarocho Veracruzano, el Anacaona, el Baleque, el Trío Criollo, los Trovadores del Ensueño, el sexteto Heroica, Moscovita y sus Guajiros, los cuartetos Pápalo Quelite y Pochote, y los más contemporáneos Pregoneros del Recuerdo o el conjunto Son y Pregón. En Yucatán la influencia cubana se empezó a sentir en diversas "Orquestas de Jarana" como la de Secundino Pech y Pedro Barrón que llegaron incluso a incorporar los timbales muy al estilo de las danzoneras y de las llamadas charangas francesas. El testimonio sonero del "Tapa" Macías, fundador del célebre "Son Clave de Oro" parece retumbar desde las paredes de su recuerdo hasta nuestros días: "...los que tocamos son aprendimos de los cubanos. En el parque Zamora había un kiosko que se llamó Siboney, ahí tocaban música de Miguel Matamoros y nosotros íbamos a oir... La feliz suerte de vivir esos años. Era una novedad. La gente siempre ha sido muy alegre. Nos dio una respuesta muy acogedora...Cuando vino el son se conjuntó toda esa alegría". ${ }^{7}$

A esto contribuyó, desde luego, el desarrollo de dos medios de comunicación que tuvieron un particular arraigo en el puerto jarocho y en la ciudad blanca del sureste: la radio y el cine. Las primeras estaciones de ondas hertzianas jarochas fueron la XEU y la XEHV, y en Yucatán la XEFC. Por sus estudios

\footnotetext{
7 Antonio García Niño, "Glosas profanas para una crónica que se construye a sí misma en el tiempo" en sí misma en el tiempo en Eslabones, No. 4 México, julio/diciembre 1992, pág.
}

Palobra No. 12. Agosto de 2010 - Julio de 2011 
pasaron algunas de las orquestas y figuras más importantes del quehacer cultural cubano e influyeron directamente a una enorme gama de músicos y artistas veracruzanos y yucatecos. Ligadas a las cadenas nacionales de radio desde la década de los años treinta, gran parte del éxito de la industria radiofónica local se debió a sus programas de concursos. La declamación, el canto y los comerciales acompañaban a las radionovelas, que provenían por lo general de la capital del país o de Cuba, para darle brillo a la emoción de estar en "el aire". En el Puerto de Veracruz desde el último piso del edificio de La Merced, en aquel pequeño estudio de la XEU las orquestas del Chato Rojas y sus Lobos Marinos, el trío La Prensa, el grupo Veracruz, y la muy veracruzana Toña la Negra, por cortesía de cigarros "Delicados" o del habanero "Isidoro Hoyos", daban a conocer sus versiones de boleros, rumbas y congas. De ahí el salto hacia la capital de la república, a los medios de comunicación capitalinos y a los centros de producción disquera y fílmica se daba de manera prácticamente natural. Tal fue el caso del grupo sonero "Clave de Oro" que ya mencionamos. Siguiendo de cerca el camino de otras grandes figuras de la música popular cubana y mexicana este grupo tuvo una carrera meteórica a partir de los años treinta. El estudioso Arturo García Niño lo confirma así:

...por alguna extraña razón el son encontró en Veracruz su casa, se asentó y se diseminó hacia el exterior, o mejor dicho, hacia el interior de México...es cierto que el Son Clave de Oro es, hasta donde el sentido lo recuerda, la agrupación musical que afirmó un movimiento oriundo del puerto que caminó largo y que todavía sigue creciendo a orillas del mar. Desde 1933 hasta el 54 deambuló junto con Toña "la Negra", Agustín Lara, Maria Antonieta Pons, Pedro Vargas, el Trio Tariácuri, los Hermanos Martínez Gil, los Bermejo; vivieron la etapa seria de la XEW, pasaron del 39 al 42 por El Patio y actuaron casi sin interrupción durante ocho años en el centro nocturno Waikikí. ${ }^{8}$

Pero volviendo a los artistas cubanos que arribaron a los medios mexicanos, hay que destacar que hubo quienes llegaron con cierta seguridad en el empleo, como comparsas en representaciones teatrales o con grupos de baile en centros nocturnos. Ninón Sevilla, por ejemplo, llegó a México, en 1946, para incorporarse a una temporada en el Teatro Degollado de Guadalajara, cuya estrella era Libertad Lamarque. Amalia Aguilar le contaría a Fernando Muñoz cómo ella y su hermana, las Hermanas Aguilar, trabajaron largas temporadas 
en importantes espacios artísticos habaneros como el Hotel Nacional, el Tropicana, el Edén Concert, la CMQ y Cadena Azul. Ambas formaron parte del elenco de la Compañía de Teatro de Cuba, en la que actuaban Martha Núñez y Arechavaleta, quienes serían sus maestros de actuación. Su encuentro en Panamá con Julio Richard, quien fuera colocador de estrellas en México, la condujo a la capital mexicana,

También hubo quienes, como los casos tempranos del Trío Matamoros, Ernesto Lecuona y Rita Montaner, que ya eran conocidos en México por la difusión de su repertorio a través de la radio, no tuvieron problemas para encontrar su camino en los medios mexicanos. Estos casos contrastan con los de aquellos que armados con sus conocimientos y capacidades musicales, como los ya mencionados Acerina, Dámaso Pérez Prado y Arturo Núñez -en sus respectivas épocas- fueron confiados a la azarosa aventura del éxito, por parte de sus contratantes, sin que tuviesen fama anticipada.

Así, es muy probable que esta historia abarque sus mejores momentos durante las décadas de los años treinta y cuarenta, mismas que plantearon un reordenamiento metropolitano del espectáculo en México. ${ }^{9}$ La apertura de salones de baile y centros nocturnos, desde el Salón México, el Salón Colonia o el Waikikí, por poner solo tres ejemplos, y la importancia de escenarios clave como fueron el Teatro Lírico, el Teatro Politeama y la XEW, además de la producción fílmica desde mediados de los años treinta fueron desde luego determinantes en esta proliferación de expresiones culturales cubanas. La relación entre empresarios, patrocinadores, intermediarios y representantes de artistas "tropicales", en todos estos sitios, fue sin duda parte fundamental en la difusión de la "cubanía" en el mundo musical mexicano. Figuras como Juan Saldaña Careaga, dueño del cabaret Java, don Lino Estrada, célebre propietario de los congales Conchita y Patria, y Eutimio Romay conocido empresario dueño del centro nocturno Bagdad fueron sin duda responsables de que muchos artistas cubanos tuvieran trabajo en el ambiente cabareteril de la capital.

La sensualidad y el erotismo tuvieron en estos lugares una nota muy ligada a la "cubanía". Las mulatas y los bongoseros eran una especie de emisarios del mundo erótico y sensual que privaba en el imaginario de lo prohibido por las buenas costumbres en la capital. Aún cuando esta "cubanía" no mostrara su tez negra o mulata, como fue el caso de Amalia Aguilar o de Celio González las referencias a lo erótico en el baile de la rumba, la conga,

9 Armando Jiménez, Sitios de rompe y rasga en la ciudad de México, México, Océano, 1998.

Palobra No. 12. Agosto de 2010 - Julio de 2011 
${ }^{10}$ Ibíd., pág. 145.

${ }^{11}$ Ibídem.

12 Yolanda Moreno Rivas, Historia de la música popular mexicana, México CONACULTA-Alianza Editorial, 1979 , pág. 240. el danzón, el mambo o el cha cha chá tenían connotaciones de negritud sensual. Parecía que el "exotismo" permitía excesos tales como la ausencia de ropa y los movimientos lujuriosos, mismos que la mojigatería nacional no aceptaba en actores y actrices identificados con el cosmopolitanismo o el nacionalismo mexicanistas.

Quizás el espacio nocturno con mayor presencia de esta "cubanía" fue el clásico Babalú que en una de sus paredes ostentaba un magnífico mural de José Gómez Rosas, alias "El Hotentote" que representaba el frenesí del baile del mambo. ${ }^{10}$ El propio Miguelito Valdés "Mister Babalú" llego a cantar en este congal y cuenta Armando Ramírez que, "...semanas después cierta mujer vendía fotos y discos de este artista, autografiados por él , en el interior del local. Como el precio era razonable, agotaba la mercancía. Pero un día se supo que ella falsificaba las firmas, fue demandada y dio con sus huesos en el tambo. "Mister Babalú" se condolió de ella y retiró la acusación". ${ }^{11}$

No hay que olvidar que muchos de estos artistas cubanos llegaban a México no sólo a cumplir con sus contratos en espacios de baile, en los escenarios capitalinos, o en las industrias cinematográficas o radiofónicas mexicanas. Las compañías disqueras, muchas de éllas transnacionales, como la RCA Víctor o la Phillips, tenían contratos con la editora musical que controlaba don Emilio Azcárraga Vidaurreta, cabeza de la Asociación Mexicana de Productores Fonográficos (Amprophon) que prácticamente monopolizaba la producción nacional de discos. A través de dicha editora los músicos cubanos registraron sus piezas y las grabaron quedando a merced del emporio mediático mexicano no sólo a través de la venta de sus productos musicales sino sobre todo a través de su difusión. Las empresas transnacionales de productos fonográficos grababan en México a los artistas cubanos y luego los promovían a nivel internacional. Tal fue el caso de la famosa Orquesta Casino de la Playa, de la Danzonera de Acerina y de la Sonora Matancera. Las tres grabaron en México durante la década de los años cuarenta sus más conocidos éxitos, participaron en emisiones radiales como los programas clásicos de los sábados en la noche en la W "Que rico vacilón" o "La hora orfeón”, y participaron en infinidad de filmaciones tanto nacionales como extranjeras. Un factor que contribuyó enormemente a que primero grabaran y se dieran a conocer en México, para luego ingresar a los mercados norteamericanos y europeos fue que durante la Segunda Guerra Mundial, las emisoras radiales de Estados Unidos y sus filiales mexicanas boicotearon a la poderosa unión de compositores y artistas del vecino del norte ASCAP. ${ }^{12}$ Esto facilitó la contratación de artistas 
y compositores latinoamericanos y practicamente el noventa por ciento del repertorio musical de estas emisoras se constituyó con material musical del centro y sur del continente, y sobre todo del área caribeña. La influencia de los latinos en el medio norteamericano podía percibirse hasta en los apodos que ostentaron algunos músicos como Pepe Domínguez "Mister Frenesí" o el ya mencionado Miguelito Valdés "Mister Babalú".

El danzón y el son cubanos se fueron convirtiendo así no solo en referencias clásicas de la cubanía musical, sino incluso en bailes de gran arraigo en todo México, principalmente el danzón, y en otras partes del mundo. La popularización del célebre antro que permitía la mezcla de distintos estratos sociales, el Salón Mexico, convertido en 1948 en titulo de una famosa película, gracias a la tríada formada por Emilio "Indio" Fernández, Gabriel Figueroa y Mauricio Magdaleno, demostró que dicho baile era una especie de "baile nacional" de congales y barriadas, que bien podía competir con el otro baile nacional que era "el jarabe tapatío" y quizás hasta ganarle en simpatía y no se diga en erotismo.

\section{III}

Desde luego hay una gran cantidad de acontecimientos o temas que aparecen de manera sincrónica, en México y el extranjero, relativos al tema del espectáculo tropical y su masificación, y que hay que descifrar con mayor detalle. Un ejemplo, sería la llegada de Rita Montaner a México, coincidente con la llegada de Carmen Miranda a Hollywood. Las dos divas de la música tropical, una cubana y la otra brasileña, salieron de sus respectivos países a principios de los años cuarenta e hicieron una

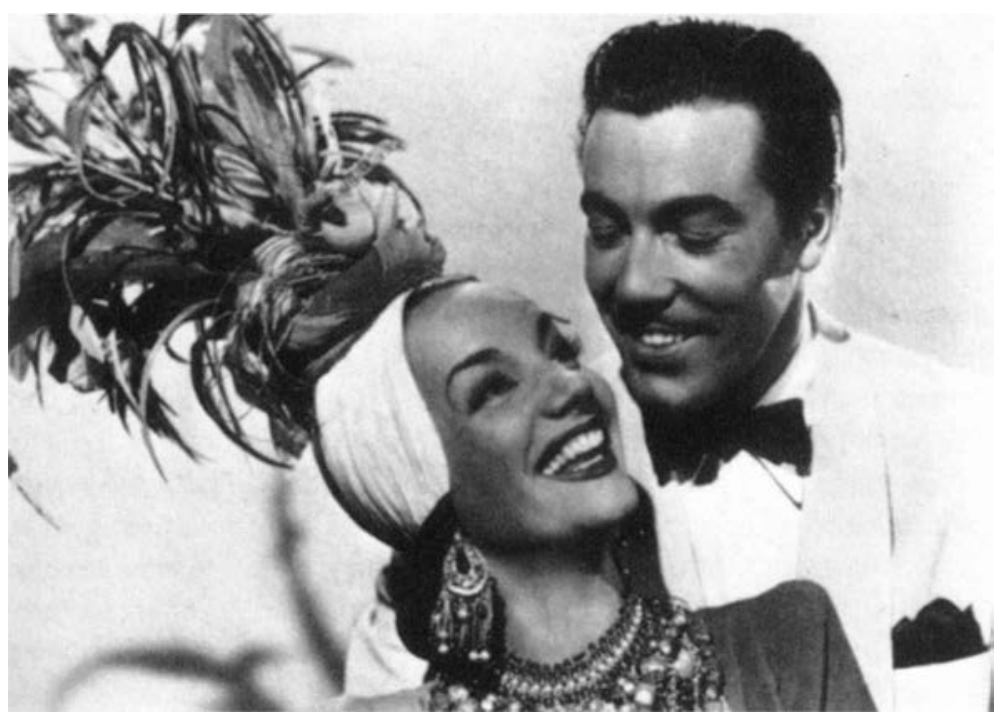

Carmen Miranda con Cesar Romero, en “'A la Habana me voy” de Walter Lang Foto de archivos de la filmoteca,de la asociación de revistas culturales de España meteórica carrera a partir de la creación de sus propios estereotipos. La brasileña con sus atuendos tropicales llenos de piñas y plátanos, y la cubana en los clásicos papeles de mulata en películas como María La O (1947) o Angelitos negros (1948) 
${ }^{13}$ Emilio García Riera, Historia documental del cine mexicano, Vol. 3, México, ERA, 1971, pág. 230.

14 Ricardo Pérez Montfort," El bolero ranchero: contribución mexicana a la historia del bolero" en Jorge Arturo Chamorro Escalante (coordinador) El bolero. Historia musical, estructura y discursoso performativo México, Universidad de Guadalajara, 2005, pág. 29-40

${ }^{15}$ Helio Orovio, Música por el Caribe, Santiago de Cuba, Editorial Oriente, 2007, pág. 140-148
Otro caso fue el del Trío Matamoros en México, que se proyectó a través de sus grabaciones con la RCA, mismas que lograron también relativo éxito en Estados Unidos, sobre todo en las comunidades latinas de la costa este. En sentido inverso Ernesto Lecuona tuvo mayor éxito en los Estados Unidos que en México. Sin embargo, sus creaciones se insertaron de manera puntual en el cine mexicano, y ahí sus puestas en escena le dieron un reconocimiento de mayor envergadura. Baste recordar una vez más aquella producción cubanomexicana María la $O$, basada en la obra lírica de Emilio Lecuona y de la cual Emilio García Riera se expresaba así: “... Este intercambio cinematográfico entre Cuba y México consistiría en que la primera daría al segundo la oportunidad de compartir la pena ante el dolor y la fatalidad de sus negros. El cine mexicano ya podría considerar como propias las dificultades de una mezcla de razas realizadas en condiciones de pecado, voluptuosidad, superstición, discriminación, adivinaciones del futuro y pasitos tan chévere". ${ }^{13}$

Otro cantar tendría que ver con la producción regional del bolero en territorio mexicano y sus contrastes. El bolero ranchero le daría a este género eminentemente caribeño un toque nacionalista mexicano que de entrada trataría de competir con compositores y artistas cubanos del propio género. Si bien compositores mexicanos como Agustín Lara o Guty Cárdenas, y cubanos como Ángel Díaz y el Niño Rivera insistieron en darle al bolero una connotación claramente caribeña, el bolero ranchero interpretado por Pedro Infante, Luis Aguilar o el mismísimo José Alfredo Jiménez intentó desplazar la sensual cubanía por un estilo autoafirmativo, melancólico y machista propio del nacionalismo mexicano. ${ }^{14}$ De cualquier manera el bolero sin más, sería uno de los múltiples vehículos musicales que permitirían la proyección de la cubanía tanto en México como en el mercado norteamericano. Como ejemplos podríamos recorrer desde el propio Trío Matamoros y Rita Montaner hasta José Antonio Méndez, pasando desde luego por Benny Moré, Olga Guillot, Celia Cruz, y Celio González, tan sólo para mencionar algunos.

La extensa dimensión temporal y la frecuencia que el espectáculo tropical tuvo en México, en contraste con lo sucedido en otras latitudes, permitió una constante inserción de novedades como lo fue el mambo en 1948, y el chá chá chá, en 1950. Es bien sabido que fue Pérez Prado desde México quien convirtió al mambo en una moda mundial. Y fue también Enrique Jorrín con su orquesta inspirada en las antiguas charangas quien lanzó su famosísima "Engañadora" desde los estudios de la XEW a la fama internacional. ${ }^{15}$ 
De esta manera el fenómeno de difusión y consumo masivo que, desde los años cincuenta, empezó a identificarse como "las modas musicales latinas" vincularían de manera indeleble el maridaje de los medios de comunicación mexicanos con la expresión popular cubana, y de ambos con el cada vez más importante mercado de productos "latinos" en los Estados Unidos de Norteamérica. Si bien, durante los años cuarenta y primeros cincuenta, la exportación mexicano-cubana de valores culturales y estereotipos se dirigió sobre todo a los mercados sudamericanos, avanzados los años cincuenta y durante prácticamente toda la siguiente década, fueron sobre todo los consumidores "latinos" de Estados Unidos los que apuntalaron el fenómeno de las "modas musicales". A ellos estuvo dedicado gran parte del encumbramiento del mambo y luego del cha cha chá; no se diga del primer jazz-latino y posteriormente el fenómeno internacionalmente conocido como la salsa.

John Storm Roberts y Arlene Dávila establecen que si bien en los años sesenta se produjo una especie de resguardo de estos valores, en gran medida determinado por la tensa relación cubano-estadounidense, la siguiente década vería una especie de "boom" de lo afroantillano en Estados Unidos, que ya no compete del todo al presente estudio. ${ }^{16}$ De cualquier manera, el primer gran auge del mundo estereotípico cubano -o si se quiere un tanto más general: afroantillano- pasó por los ambientes urbanos y los medios de comunicación masiva mexicanos. No en vano el cine de cabareteras, rumberas y exóticas tiene un sello que remite invariablemente a la cultura popular de los años cuarenta y cincuenta. Se trató pues de una interpretación muy particular de música, baile, actitudes y, en general, de estereotipos culturales "cubanomexicanos".

En el capítulo titulado, "Se formó la rumba", de su libro Alta frivolidad, Margo Su dibujó una espléndida imagen de la inserción de la rumba en el panorama del espectáculo en México. ${ }^{17}$ Este vívido relato nos permite conocer, a través de una testigo sensible, las características de un producto cultural cubano que fue asimilado de manera definitiva en la vida urbana mexicana, a pesar de que incluía códigos que, por aquellos años, -estamos hablando de los cuarenta- en México no habían sido del todo descifrados, como fueron los componentes afrocubanos de la música y el baile y la imagen. Los mexicanos -desde hacía por lo menos dos décadas- se encontraban demasiado ocupados interpretando su propia mexicanidad, en la cual no incluían al ingrediente negro. Poco a poco se fueron incorporando los nuevos estereotipos que el crecimiento urbano y la modernización les ofrecían.
16 John Storm Roberts, El toque latino. El impacto de la música lationoamericana en los Estados Unidos, México, EDAMEX, 1982 y Arlene Davila, Latinos Inc. The Marketing and Making of a People, EUA, University of California Press, 2001.

17 Margo Su, Alta frivolidad, México. Cal y Arena, 1990, pág. 40-43. 
Al fin de la Segunda Guerra Mundial las calles se llenaron de miradas incrédulas al escuchar a los voceadores cantar la noticia. Faltaría tiempo para comprender hacia dónde se encaminaban las nuevas ofertas culturales y cómo se cosecharían en las distintas latitudes. En Cuba y México se experimentaron procesos similares. Las pesquisas en torno a lo cubano y lo mexicano se hicieron cada vez más importantes, ya que para aquellas fechas sus frutos en el terreno comercial de medios masivos como la radio y el celuloide empezaban a rendir dividendos por demás interesantes. Por ejemplo, el cineasta hispanocubano Juan Orol realizó en México la mayor parte de su obra y descubrió, a fines de 1938 con su película Siboney -producida en locaciones cercanas a La Habana- las posibilidades que prometía en el mercado del espectáculo la representación de la rumbera, así como también la del "negrito bembón con sus mangas de tupidos olanes", en otros territorios.

La ya citada Margo Su cuenta cómo, "esta imagen toma por asalto la memoria". Ella misma se refiere al "negrito" haciendo "...filigranas coreográficas al ritmo de las tumbas y el bongó, y gira con elegancia sobre un solo pié. La rumba es Cuba, con sus palmeras borrachas y dos maracas en cruz flotando en el paisaje. Es el cajón humilde tocado en el solar de los pobres, y la mulata de chancletas como adorno alrededor del negrito brilloso color tizón."18

La rumbera, por su parte, fue el sex symbol de la posguerra. Grupos de mujeres cubanas emigraron hacia el continente, en especial a Panamá y México, con las caderas preparadas para moverse cadenciosa y lujuriosamente ante el primer compás de las percusiones. Aunque no fueran negras y solo en algunos casos mulatas sugeridas, las alusiones eróticas y las sensualidades tropicales de sus espectáculos incluyeron siempre una buena dosis de negritud.

En México el fenómeno rumbero se expandió de manera vertiginosa. Después del arribo de María Antonieta Pons, una de las primeras rumberas cubanas en pisar los escenarios teatrales y cabaretiles mexicanos, el negro se colocó a su lado como el comparsa definitivo de sus propuestas escénicas. Le siguieron Amalia Aguilar, la mexicana Mercedes Barba, Ninón Sevilla y Rosa Carmina. Todas ellas, "envueltas en piñas, moños, olanes, cocos, encajes rebordados de lentejuelas y plumas chillantes, música brillante y erotismo" se hicieron acompañar por los rostros negros de Kiko Mendive, Dámaso Pérez Prado, Silvestre Méndez, Tabaquito o Jimmy Monterrey.

La supuesta indecencia o la rayana obscenidad de los bailes ejecutados por las rumberas, cupo muy bien en el molde del melodrama. Estas mujeres dejaron 
de ser ingenuas ejecutoras de ritmos embalados en el equipaje racial, para ser protagonistas de los dramas de la prostitución, el adulterio, la infelicidad. La adopción y asimilación de los recursos escénicos afrocubanos tomó otros vuelos y se hizo más compleja. La mirada puesta en la pantalla grande ya no se detuvo en las caderas licenciosas sino en los valores perdidos sin posibilidad de redención. Cientos de filmes de la época de oro del cine mexicano dejaron ver este rompecabezas cultural y confirmaron que sí hubo planteamientos discriminatorios en la caracterización de lo negro en México.

Es así como algunos acontecimientos mediáticos de los años cuarenta y cincuenta definieron la forma como se representó "lo tropical" en la cultura visual mexicana. Transcurrieron cantidad de procesos empalmados, para que la imagen de "lo negro cubano" sintetizada y reforzada, fuera apreciada en el cine de rumberas y saliera del fenómeno radial insular protagonizado por El derecho de nacer -radionovela de Félix B. Caignet, producida por primera vez en 1948-, así como en la proyección de estos hacia México. Ambos productos, que explotaron los recursos afrocubanos, brindaron herramientas escénicas para sugerir en México un mestizaje en el que participaba otro recurso además del español y el del indio: el de la raíz africana al que no se hacía referencia sino de manera simulada o indirecta.

Para llegar a El derecho de nacer, cientos de escritores, actores, productores y músicos cubanos, desde fines del siglo XIX, definieron un catálogo de estereotipos culturales con los que retroalimentaron los discursos acerca de la identidad nacional. En este catálogo hubo decenas de versiones de negros y negras personificados que tuvieron como un primer escenario al teatro popular y la lírica, y más adelante la radio y el cine, hasta llegar a la televisión: negras ancianas y sabias, negras oportunistas, negras conflictivas, negras sensuales; negros viejos y sabios, negros pícaros, negros seductores. ${ }^{19} \mathrm{Y}$ esta negritud volcada en lo mulato diferenciado, reaparecía como parte de la lista de personajes que repetían el catálogo anterior.

Este proceso, dicho aquí de manera rápida, tuvo una de sus etapas de auge y difusión masiva en Cuba entre los años veinte y treinta, con las empresas del teatro frívolo y las agrupaciones musicales. Todavía entonces seguía siendo, de alguna manera, un producto local. A pesar de que la masificación del danzón y el son en territorio mexicano se había dado mucho antes, como hemos visto, la verdadera proyección del imaginario afrocubano se dio con la radio y el cine, en los años cuarenta. ${ }^{20}$ La representación de lo negro en México, al

19 Gabriela Pulido Llano, Mulatas y negros cubanos en la escena mexicana 1920-1950, México, INAH, 2010 .

20 Robin D. Moore, Nationalizing blackness. Afrocubanismo and artistic revolution in La Habana, 19201940, EUA, University of Pittsburg Press, 1997.

Palobra No. 12. Agosto de 2010 - Julio de 2011 
elegir los productos culturales cubanos como herramientas escénicas, se nutrió indirectamente de aquel imaginario hasta convertirse en referencia central a la hora de incorporar la raíz negra o mulata a los asuntos del mestizaje y sus múltiples expresiones.

Es en este escenario que la radionovela cubana comenzó a destacar y se encumbró con Félix B. Caignet, escritor de El derecho de nacer, como protagonista central. La famosa escritora de radionovela y telenovela en México, Fernanda Villeli, defendió siempre que el género de la radionovela se importó de Cuba. El fenómeno de la imagen mediática de lo negro no se detuvo ahí, vendrían a consolidar la imagen otras producciones que, como veremos, circunscribieron la presencia negra al melodrama, como si esta hubiese sido fabricada para dicha forma de expresión. Sin embargo, esta es ya otra historia que podría contarse acompañada por la inevitable pieza de Andrés Eloy Blanco "Angelitos negros".

\section{BIBLIOGRAFÍA}

Chamorro Escalante, Jorge Arturo (coordinador) El bolero. Historia musical, estructura y discursoso performativos, México, Universidad de Guadalajara,2005

Dávila, Arlene, Latinos inc. The marketing and making of a people, EUA, University of California Press, 2001.

García Diaz, Bernardo y Sergio Guerra Vilaboy (coord) La Habana /Veracruz. Veracruz/ La Habana. Las dos orillas, Universidad Veracruzana, Universidad de la Habana, México, 2002.

García, Gustavo y Rafael Aviña , Época de oro del cine mexicano, México, Editorial Clío, México, 1997.

García Niño, Antonio, "Glosas profanas para una crónica que se construye a sí misma en el tiempo" en Eslabones, No. 4 México, Julio/Diciembre 1992.

García Riera, Emilio, Historia documental del Cine Mexicano, Vol. 3, México, ERA, 1971.

Jiménez, Armando, Sitios de rompe y rasga en la ciudad de México, México, Océano, 1998.

Moore, Robin D., Nationalizing blackness. Afrocubanismo and artistic revolution in La Habana, 19201940, EUA, University of Pittsburg Press, 1997.

Moreno Rivas, Yolanda. Historia de la música popular mexicana, México, Conaculta-Alianza Editorial, 1979.

Muñoz Laura (coord.), México y el Caribe. Vínculos, intereses, región, 2 tomos, Instituto Mora, México, 2002.

Muñoz Castillo, Fernando, Las reinas del trópico, México, Azabache, 1993. 
Orovio, Helio. Música por el Caribe, Santiago de Cuba, Editorial Oriente, 2007

Pérez Montfort, Ricardo, Expresiones populares y estereotipos culturales en México. Siglo XIX y XX. Diez ensayos, CIESAS, México, 2007.

"Folklore e identidad, Reflexiones sobre una herencia nacionalista en América" en Avatares del nacionalismo cultural. Cinco ensayos, CIESAS-CIDEHM, México, 2000.

Pulido Llano, Gabriela. Mulatas y negros cubanos en la escena mexicana, 1920-1950, México, INAH, 2010.

Sánchez, Francisco, Crónica antisolemne del cine mexicano, México, Universidad Veracruzana, 1989.

Storm Roberts, John, El toque latino. El impacto de la música lationoamericana en los Estados Unidos, México, EDAMEX, 1982.

Su, Margo, Alta frivolidad, México, Cal y Arena, 1990.

Palobra No. 12. Agosto de 2010 - Julio de 2011 